\title{
Neurological soft signs and cognition in the late course of chronic schizophrenia: a longitudinal study
}

\author{
Christina J. Herold ${ }^{1}$ (1) · Céline Z. Duval ${ }^{1}$. Johannes Schröder ${ }^{1}$
}

Received: 7 November 2019 / Accepted: 4 May 2020 / Published online: 16 May 2020

(c) The Author(s) 2020

\begin{abstract}
Neurological soft signs (NSS) are minor ('soft') neurological abnormalities in sensory and motor performances, which are frequently reported in patients with schizophrenia at any stage of their illness. It has been demonstrated that NSS vary in the clinical course of the disorder: longitudinally NSS decrease in parallel with remission of psychopathological symptoms, an effect which mainly applies to patients with a remitting course. These findings are primarily based on patients with a first episode of the disorder, while the course of NSS in patients with chronic schizophrenia and persisting symptoms is rather unknown. Therefore, we investigated NSS twice in 21 patients with chronic schizophrenia (initial mean duration of illness: $23 \pm 11$ years) with a mean follow-up interval of 7 years. NSS were evaluated by the Heidelberg Scale, established instruments were used to rate neuropsychological performance and psychopathological symptoms. NSS showed significant increases on the subscales "motor coordination" and "integrative functions", while positive and negative symptoms, including apathy, showed only minor, non-significant changes. Verbal memory, verbal fluency, and cognitive flexibility along with severity of global cognitive deficits demonstrated a significant deterioration. Regression analyses identified executive dysfunction (cognitive flexibility and verbal fluency) at baseline as significant predictors of NSS increase at follow-up. Our findings indicate that NSS deteriorate in the long-term course of chronic schizophrenia. This effect may be accounted for by a decrease of executive functions and logical memory, which can be attributed to premature brain aging.
\end{abstract}

Keywords Neurological soft signs $\cdot$ NSS $\cdot$ Chronic schizophrenia $\cdot$ Follow-up $\cdot$ Neuropsychology $\cdot$ Psychopathology

\section{Introduction}

Neurological soft signs (NSS) represent a variety of discrete abnormalities in sensory integration, motor coordination and sequencing of complex motor acts and are demonstrated in the majority of patients with schizophrenia, including neuroleptic-naïve first-episode patients and chronic cases [1-4].

Previous studies clearly show that NSS are not a static feature of schizophrenia, but instead vary in the clinical course of the disorder. This effect was confirmed in a metaanalysis based on 17 longitudinal studies, which yielded a reduction of NSS in the course of acute psychosis paralleling

Communicated by Peter Falkai.

Christina J. Herold

christina-j.herold@med.uni-heidelberg.de

1 Section of Geriatric Psychiatry, Department of General Psychiatry, University of Heidelberg, Voßstr. 4, 69115 Heidelberg, Germany the remission of psychopathological symptoms [5]. However, NSS scores did not normalize to the levels typically found in healthy controls. Recently, Bachmann and Schröder [6] presented an overview about 29 follow-up studies, which addressed NSS longitudinally in patients with schizophrenia at different stages of their illness. While patients with a first-episode or a remitting course predominantly showed a decrease of NSS scores over time, levels of NSS increased in those with an unfavorable, chronic course. With respect to effects of medication, there seems to be a relationship between medication response and improvement of NSS scores independent of the type of antipsychotics.

Moreover, in a longitudinal MRI (magnetic resonance imaging)-study of our group, Kong et al. [7] confirmed this dichotomization, which was reflected by the underlying cerebral changes: 20 patients with first-episode schizophrenia (mean age: $25.6 \pm 7.2$ years) were investigated twice, after remission of the acute symptoms and after a followup period of one year. While patients with decreasing NSS scores showed rather minor and localized changes within the 
left frontal lobe, cerebellum and cingulate gyrus, patients with persistent NSS scores demonstrated pronounced gray matter (GM) reductions over time. Their more unfavorable course was associated with GM decreases of the sublobar claustrum, cingulate gyrus, cerebellum, frontal lobe and middle frontal gyrus. These findings correspond to results from other longitudinal and cross-sectional (first-episode vs. chronic schizophrenia) MRI-studies, which yielded progressive structural brain abnormalities in schizophrenia in frontal, cingulate and cerebellar regions [for review see: 8 , 9-11].

While neuropsychological deficits are among the core features of schizophrenia [12-15], studies of patients with chronic schizophrenia demonstrated that their test performance further decreases [16-18]. An age-associated cognitive decline seems to be especially pronounced in some domains such as cognitive flexibility [12]. These findings were contrasted by a rather stable psychopathological profile cross-sectionally with unchanged negative symptoms and slightly elevated positive symptoms in the youngest subgroup [12, 19].

Along with risk factors such as lower educational attainment, persistent psychopathology and advanced age that may increase cognitive decline in older individuals with schizophrenia, concomitant physical diseases like hypertension, adiposity or diabetes mellitus might also contribute to the observed cognitive and functional decline in older patients with a chronic course of the disease [20-22]. However, only a few studies focused on patients with chronic schizophrenia and/or the course of the disorder during late adulthood. This issue is of particular relevance given the growing number of older patients with schizophrenia [23].

The aim of the present study was to investigate the longitudinal course of NSS in a sample of severely disabled patients with chronic schizophrenia. Based on the given literature, we expected NSS scores to further increase over time, accompanied by a deterioration of neurocognitive functions.

\section{Methods}

\section{Subjects}

We examined 21 patients with chronic schizophrenia $(N=18)$ or schizoaffective $(N=3)$ disorder [DSM-IV criteria, 24] twice, 2008/2009 (T1) and 2015-2017 (T2) (see Table 1). Patients were recruited from three psychiatric long-term units (T1: $N=20, \mathrm{~T} 2: N=13)$ and a mental state hospital (T1 and T2: $N=1$ ), respectively; at $\mathrm{T} 2,7$ patients had been placed in nursing homes. Patients were treated with antipsychotic medication according to their psychiatrists' choice. Initially, all but 4 patients received exclusive
Table 1 Demographic and clinical characteristics

\begin{tabular}{lll}
\hline & $\begin{array}{l}\text { T1 } n=21 \\
\text { Mean (SD) }\end{array}$ & $\begin{array}{l}\text { T2 } n=21 \\
\text { Mean (SD) }\end{array}$ \\
\hline Education, years & $11.67(2.46)$ & \\
Sex, $N, \%$ masculine & $15,71.4 \%$ & \\
Duration of illness, years & $23.05(11.09)$ & $30.71(9.97)$ \\
Age, years & $45.33(8.71)$ & $52.71(8.70)$ \\
Age at illness onset, years & $22.00(8.40)$ & \\
\hline
\end{tabular}

atypical antipsychotics, at the follow-up evaluation 8 patients received both, atypical and typical antipsychotic medication, and one received typical antipsychotic medication only.

Psychiatric history of the patients was retrieved from medical records. Given that our sample almost exclusively comprised severe disabled patients living in psychiatriclong-term units, physical comorbidities as hypertension (T2 $N=11)$, adiposity (BMI $\geq 30, \mathrm{~T} 2 N=10)$, diabetes mellitus (T2 $N=7$ ), hyperlipidemia (T2 $N=14$ ), nicotine abuse (T2 $N=15)$ or alcohol/drug abuse in the past (T2 $N=5)$ were frequently diagnosed. Patients with extrapyramidal side effects, akathisia, parkinsonian signs and abnormal involuntary movements were excluded before study entry, as it was the case for patients with late onset schizophrenia, i.e., with a manifestation of the disease after age 40 [16]. Due to the chronicity of illness, not all participants were able to perform all neuropsychological tasks and NSS items. ${ }^{1}$

The investigations were approved by the ethics committee of the Medical Faculty, Heidelberg University. After full explanation of the proceedings, subjects provided written informed consent to participate in accordance with the Declaration of Helsinki.

\section{Clinical and neuropsychological assessments}

Psychopathological symptoms were assessed on the Brief Psychiatric Rating Scale [BPRS, 25], the Scales for the Assessment of Positive and Negative Symptoms [SAPS and SANS, 26, 27] and the Apathy Evaluation Scale [AES, 28, 29].

NSS were examined with the Heidelberg Scale [2, 30] that comprises motor and sensory NSS. The scale consists of five items assessing motor coordination, ${ }^{2}$ three items

\footnotetext{
${ }^{1}$ In case of NSS-items we had the following number of missing data: NSS total score (T1:3/T2:3), motor coordination (T1:2/T2:0), integrative functions (T1:3/T2:2), complex motor tasks (T1:2/T2:0), right/ left and spatial orientation (T1:2/T2:3), hard signs (T1:2/T2:0). If one item was missing, the respective subscore and the sumscore were not calculated.

2 Motor coordination: Ozeretski's test, diadochokinesis, pronation/ supination, finger-to-thumb opposition, speech and articulation.
} 
Table 2 Baseline and follow-up psychopathological characteristics

\begin{tabular}{llllll}
\hline & T1 & T2 & $t$ & $d f$ & $p$ \\
& Mean (SD) & Mean (SD) & & & \\
\hline SAPS Sum Score & $15.43(16.14)$ & $12.62(12.46)$ & 0.826 & 20 & 0.418 \\
SANS Sum Score & $25.14(15.84)$ & $22.52(15.46)$ & 0.553 & 20 & 0.587 \\
AES Sum Score & $27.20(10.49)$ & $26.25(11.42)$ & 0.508 & 19 & 0.617 \\
BPRS Sum score & $20.05(11.19)$ & $15.86(6.96)$ & 1.456 & 20 & 0.161 \\
BPRS Anxiety/depression & $7.19(5.08)$ & $5.57(3.84)$ & 1.354 & 20 & 0.191 \\
BPRS Anergia & $5.43(4.98)$ & $5.10(3.53)$ & 0.250 & 20 & 0.805 \\
BPRS Thought disturbance & $4.24(4.12)$ & $3.43(3.78)$ & 0.795 & 20 & 0.436 \\
BPRS Activity & $1.71(2.05)$ & $0.91(1.34)$ & 1.602 & 20 & 0.125 \\
BPRS Hostility/suspiciousness & $1.48(2.23)$ & $0.86(1.35)$ & 1.069 & 20 & 0.298 \\
Chlorpromazine equivalents, mg & $459.62(274.65)$ & $562.88(292.44)$ & -1.526 & 20 & 0.143 \\
\hline
\end{tabular}

AES Apathy evaluation scale, BPRS Brief psychiatric rating scale, SANS Scale for the assessment of negative symptoms, SAPS Scale for the assessment of positive symptoms assessing integrative functions, ${ }^{3}$ two items assessing complex motor tasks, ${ }^{4}$ four items assessing right/left and spatial orientation ${ }^{5}$ and two items assessing hard signs. ${ }^{6}$ Ratings are given on a $0-3$ point scale (no/slight/moderate/marked abnormality). The psychometric properties of the Heidelberg Scale are well established in previous studies [2, 31].

The neuropsychological test battery included the Mini Mental State Examination (MMSE) as cognitive screening instrument [32], the subtests logical memory I (immediate recall) and II (delayed recall) from the Wechsler Memory Scale-Revised [WMS-R, 33] for the assessment of verbal memory, the digit span forward and backward tasks from the WMS-R [33] for evaluation of short-term and working memory, Trail Making Test version A and B [TMT, 34] for testing psychomotor speed and cognitive flexibility, respectively, and the verbal fluency task "Animal Category " from the CERAD (Consortium to Establish a Registry for Alzheimer's Disease) battery [35].

At T2 diagnoses, psychopathological symptoms, NSS and neuropsychological performance were reassessed using the indicated instruments. The interval amounted to a mean of 7.38 years ( \pm 0.92 , range $5-9$ years).

\section{Statistical analyses}

Statistical analyses were performed with SPSS version 23 (IBM SPSS Statistics) and $\alpha$ level of 0.05 was applied for all statistical tests.

\footnotetext{
${ }^{3}$ Integrative functions: gait, tandem walking, two-point discrimination.

${ }^{4}$ Complex motor tasks: finger-to-nose test, fist-edge-palm test.

5 Right/left and spatial orientation: right/left orientation, graphesthesia, face-hand test, stereognosis.

${ }^{6}$ Hard signs: arm-holding test, mirror movements.
}

Dependent $t$ tests were used to calculate changes over time in psychopathology, NSS and neurocognition. In case of TMT B, we used McNemar test instead.

Bivariate correlations (Pearson's $r$ ) were calculated to analyze potential associations between NSS scores and age and chlorpromazine (CPZ) equivalents, respectively.

Moreover, NSS scores that had changed significantly at the follow-up evaluation (=dependent variables) were entered in a hierarchical stepwise linear regression analysis to detect possible predictors of NSS changes. Age, years of education and duration of illness at $\mathrm{T} 1$ were introduced in the model as covariates (method: enter). As predictors, we used those clinical variables at $\mathrm{T} 1$ that changed significantly or with trend-level significance over time.

\section{Results}

\section{Psychopathological characteristics and neuropsychology}

As summarized in Table 2, none of the psychopathological characteristics changed significantly during the follow-up period. This was also the case for the average dose of $\mathrm{CPZ}$ equivalents.

Patients' cognitive performance declined significantly over time (see Table 3); this was the case for general cognitive abilities (MMSE, $p<0.03$ ), verbal memory (logical memory I and II, $p<0.05)$, verbal fluency $(p=0.05)$ and, trend-level significance only, for psychomotor speed (TMT A, $p=0.055$ ). However, three patients could not perform this test at $\mathrm{T} 2$. In case of cognitive flexibility (TMT B) about $60 \%$ of the patients were not able anymore to perform this test at follow-up assessment. McNemar test demonstrated a statistically significant difference in 
Table 3 Baseline and follow-up neuropsychological parameters
Table 4 Baseline and follow-up NSS scores

\begin{tabular}{llllll}
\hline & T1 & T2 & $t$ & $d f$ & $p$ \\
& Mean (SD) & Mean (SD) & & & \\
\hline Mini Mental State Examination & $26.19(3.88)$ & $24.14(4.45)$ & 2.495 & 20 & $\mathbf{0 . 0 2 1}$ \\
Logical memory I & $14.57(8.18)$ & $11.14(8.22)$ & 2.498 & 20 & $\mathbf{0 . 0 2 1}$ \\
Logical memory II & $10.19(7.05)$ & $7.33(8.42)$ & 2.107 & 20 & $\mathbf{0 . 0 4 8}$ \\
Digit span forward & $5.90(1.71)$ & $5.85(1.60)$ & 0.160 & 19 & 0.874 \\
Digit span backward & $4.95(2.09)$ & $4.20(2.44)$ & 1.543 & 19 & 0.139 \\
Trail making test A & $55.28(23.72)$ & $71.67(38.01)$ & -2.061 & 17 & 0.055 \\
Trail making test B & $183.52(68.54)$ & a & & & $\mathbf{0 . 0 0 0}^{\text {b }}$ \\
Verbal fluency & $17.52(5.29)$ & $15.43(6.40)$ & 2.071 & 20 & $\mathbf{0 . 0 5 1}$ \\
\hline
\end{tabular}

Bold values indicate $(p \leq 0.05)$

${ }^{\mathrm{a}} 12$ patients $(=57.1 \%)$ were not able to perform this test at $\mathrm{T} 2$

${ }^{\mathrm{b}} \mathrm{McNemar}$ test $(2$ sided)

\begin{tabular}{llllll}
\hline & T1 & T2 & t & $d f$ & $\mathrm{p}$ \\
& Mean (SD) & Mean (SD) & & & \\
\hline NSS total score & $18.50(12.47)$ & $24.31(16.51)$ & -1.865 & 15 & 0.082 \\
Motor coordination & $7.53(6.21)$ & $10.53(6.86)$ & -2.179 & 18 & $\mathbf{0 . 0 4 3}$ \\
Integrative functions & $3.41(2.92)$ & $5.06(2.88)$ & -2.441 & 16 & $\mathbf{0 . 0 2 7}$ \\
Complex motor tasks & $3.11(2.51)$ & $3.63(3.08)$ & -0.826 & 18 & 0.419 \\
Right/left and spatial orientation & $4.25(3.47)$ & $5.00(4.93)$ & -0.812 & 15 & 0.430 \\
Hard signs & $1.32(1.64)$ & $2.68(2.45)$ & -1.728 & 18 & 0.101 \\
\hline
\end{tabular}

Bold values indicate $(p \leq 0.05)$
Fig. 1 Change of NSS over time $(\mathrm{T} 1, \mathrm{~T} 2)$ in each individual subject (0-21), NSS subscale "motor coordination"

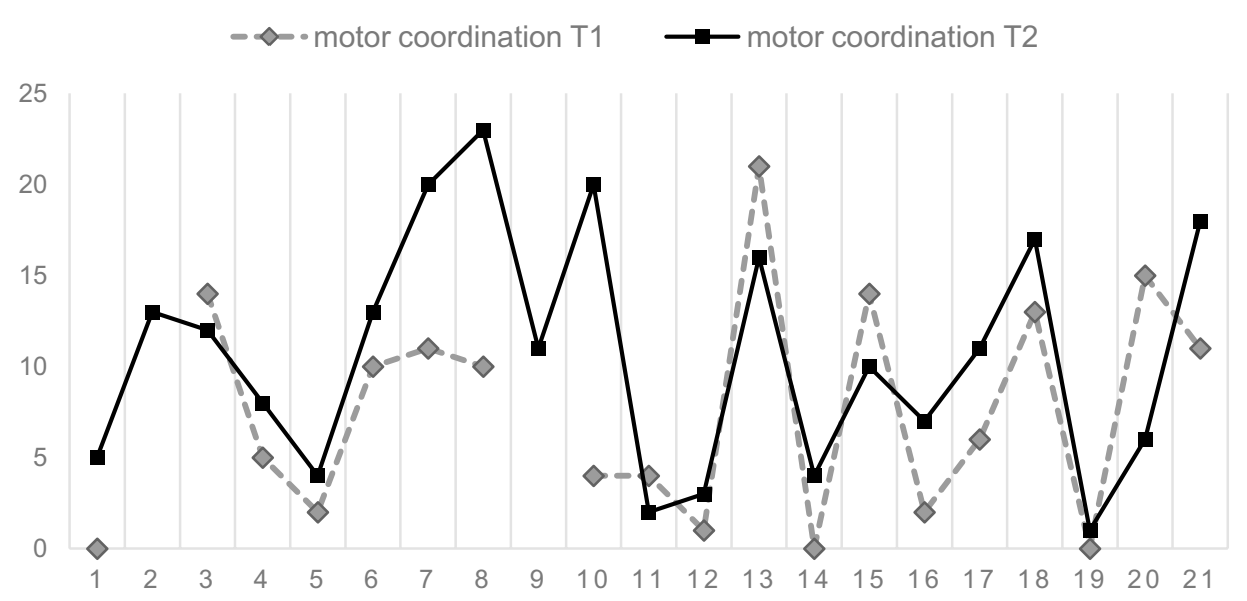

the proportion of performers of TMT B at $\mathrm{T} 1$ and $\mathrm{T} 2$ $(p<0.001)$.

\section{Neurological soft signs}

While patients' mean initial NSS total score did not change significantly $(p>0.08)$ over time, the scores of the subscales "motor coordination" and "integrative functions" increased significantly $(p<0.05)$ during the follow-up period (Table 4; Figs. 1, 2).

The calculation of Pearson's correlation coefficients between NSS total scores and age or CPZ equivalents, respectively, yielded no significant results for T1 $(p>0.10)$, and the same applied for T2 $(p>0.06)$.

To identify predictors of NSS increase, we calculated regression analyses for the subscales "motor coordination" 
Fig. 2 Change of NSS over time (T1, T2) in each individual subject (0-21), NSS subscale "integrative functions"

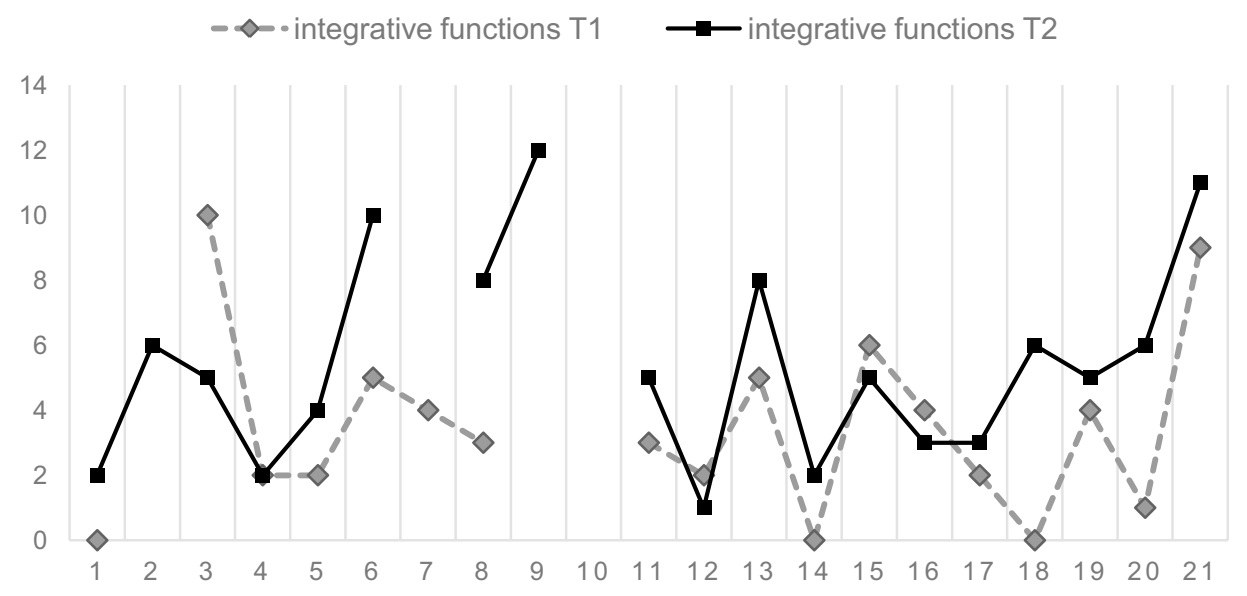

Table 5 Results of regression analyses

\begin{tabular}{|c|c|c|c|c|c|c|c|c|}
\hline & Variable & Standardized Beta & $T$ & $p$ & $R^{2}$ & $F_{\text {[df] }}$ & $R^{2}$ change & Sign. F change \\
\hline \multicolumn{9}{|c|}{ NSS subscore "motor coordination" } \\
\hline \multirow[t]{4}{*}{ Model 1} & & & & & 0.170 & $\mathrm{~F}[3,17]=2.368$ & 0.295 & 2.368 \\
\hline & Age & 0.492 & 1.768 & 0.095 & & & & \\
\hline & Education & -0.279 & -1.314 & 0.206 & & & & \\
\hline & Duration of illness & 0.059 & 0.219 & 0.829 & & & & \\
\hline \multirow[t]{5}{*}{ Model 2} & & & & & 0.342 & $\mathbf{F}[1,16]=3.598 *$ & 0.179 & $5.434 *$ \\
\hline & Age & 0.430 & 1.725 & 0.104 & & & & \\
\hline & Education & -0.132 & -0.660 & 0.518 & & & & \\
\hline & Duration of illness & 0.286 & 1.100 & 0.288 & & & & \\
\hline & Verbal fluency & -0.486 & -2.331 & 0.033 & & & & \\
\hline \multicolumn{9}{|c|}{ NSS subscore "integrative functions" } \\
\hline \multirow[t]{4}{*}{ Model 1} & & & & & 0.160 & $\mathrm{~F}[3,15]=2.146$ & 0.300 & 2.146 \\
\hline & Age & 0.308 & 0.935 & 0.364 & & & & \\
\hline & Education & -0.297 & -1.254 & 0.229 & & & & \\
\hline & Duration of illness & 0.250 & 0.793 & 0.440 & & & & \\
\hline \multirow[t]{5}{*}{ Model 2} & & & & & 0.486 & $\mathbf{F}[1,14]=\mathbf{5 . 2 4 8}^{* *}$ & 0.300 & $10.486 * *$ \\
\hline & Age & -0.108 & -0.376 & 0.713 & & & & \\
\hline & Education & 0.032 & 0.153 & 0.880 & & & & \\
\hline & Duration of illness & 0.358 & 1.438 & 0.173 & & & & \\
\hline & Trail making Test B & 0.671 & 3.238 & 0.006 & & & & \\
\hline
\end{tabular}

${ }^{*} p \leq 0.05, * * p \leq 0.01$

and "integrative functions", which changed significantly over time. As predictor variables, we used raw scores of the tests MMSE, logical memory I and II, verbal fluency, TMT $\mathrm{A}$ and $\mathrm{B}$ at T1. These analyses identified verbal fluency and TMT B performance at first examination to be significant predictors for NSS changes, while age, education and duration of illness did not contribute significantly to the models (Table 5).

\section{Discussion}

This study aimed at investigating the course of NSS and cognition in patients with chronic schizophrenia. Two main findings emerged: (1) Scores of the NSS subscales "motor coordination" and "integrative functions" increased significantly during the follow-up interval of 7 years. (2) General cognition, verbal memory as well as executive functions declined significantly over time, while psychopathological symptoms remained rather stable. In addition, executive 
functions at baseline were the strongest predictors for NSS changes.

Our findings of increasing NSS subscores in middle-aged patients with chronic schizophrenia are well in line with a recent review of the literature [6] that supports a worsening of NSS over time in chronic schizophrenia; an effect which was already demonstrated in a previous meta-analysis [5]. However, older patients with a chronic course of the disorder were only scarcely investigated: a recent cross-sectional study of our own group [19] with a chronically ill patient sample divided into three age groups (mean duration of illness: $3.2,17.3,35.6$ years) yielded a significant effect of age on NSS, with increasing NSS scores in both, patients and healthy controls with increasing age. This effect was more pronounced in patients than controls, thus indicating that the increase of NSS in chronic schizophrenia exceeded age-associated changes. In contrast, Smith et al. [36] concluded that NSS (Neurological Evaluation Scale/NES) may be a rather stable, trait-like phenomenon in 37 chronically hospitalized patients with schizophrenia (mean duration of illness $22 \pm 9$ years) which were evaluated repeatedly over a 5 -year period.

However, Chen and colleagues [37] examined NSS in 43 stable chronic schizophrenic patients (mean duration of illness $23.5 \pm 8.5$ years) twice over a 3 -year period. Scores on NSS subscales (Cambridge Neurological Inventory/CNI) 'motor coordination', 'sensory integration' and 'disinhibition' increased significantly over time, while symptoms and medication remained largely unchanged as well as the subscales 'pyramidal', 'extrapyramidal', 'dyskinesia' and 'catatonia' signs. This NSS increase seemed to be unrelated to age and illness duration, symptoms or medication. These results were interpreted as much as the authors suggested that NSS could be a marker being sensitive to a possible late deterioration process in the course of schizophrenia.

Moreover, Chan et al. [38] recently described NSS as robust biomarkers for the discrimination between individuals in different stages of the schizophrenia spectrum from healthy controls, after having examined NSS in patients with first-episode schizophrenia, individuals with ultra-high risk for psychosis, subjects with schizotypy and healthy controls $(N=39$ in each group). In addition, it has been shown that certain sub-items of NSS (CNI: motor coordination and total score) and neurocognitive performance (MATRICS Consensus Cognitive Battery: information processing speed, reasoning skill, verbal learning and attention) might be endophenotypes of schizophrenia: remitted patients with schizophrenia, their first-degree unaffected relatives and healthy controls ( $N=86$ in each group) could most accurately $(71.2 \%)$ be classified with these sub-items working as a composite endophenotype [39]. Taken together, these findings imply that NSS (in combination with neurocognition) may be used as markers for an early identification of both, high-risk individuals and those patients with a rather unfavorable, chronic course.

An accelerated deterioration of executive functions (cognitive flexibility) in elderly patients with chronic schizophrenia has been recently confirmed in an own cross-sectional design [12], as previous studies already described a worsening of executive functions, processing speed and verbal learning cross-sectionally [40-42]. These findings were extended in the present study which identified executive dysfunction as a significant predictor of NSS increase over time in chronic schizophrenia.

In contrast, Heaton et al. [43], who investigated 142 patients with chronic schizophrenia (mean duration of illness: $19 \pm 14$ years) reported neuropsychological impairments in ambulatory persons with schizophrenia to remain rather stable over 5 years. However, authors emphasized that these results may not be generalizable to institutionalized poor-outcome patients, which were not represented by their study. Similarly, Savla et al. [44] found cognitive impairments to be stable over time (on average: 15 months) among 143 outpatients with schizophrenia (mean age: $53 \pm 9$ years), though, the follow-up interval in this trial was much shorter than in the present study.

According to our results, deteriorating NSS in the longitudinal course of chronic schizophrenia go along with decreasing performance in executive functions and verbal memory. This effect may be attributed to premature brain aging following the concept of accelerated aging in schizophrenia [45], which parallels Kraepelin's original concept of dementia praecox [46]. Severe concomitant diseases such type II diabetes mellitus or hypertension may provide an additional explanation, since the latter are associated with cognitive impairments in an otherwise healthy population $[47,48]$.

Besides NSS and cognitive impairments psychopathological symptoms are affected by age and the aging process. While the severity of positive symptoms seems to diminish slightly in later life [for overview see: 16, 17], negative symptoms are generally considered to increase in the older, chronically ill; however, this dissociation was only partially confirmed in classical studies, which also found a "second, positive knick" even decades after manifestation of the disease instead [49-51]. In our sample no significant psychopathological changes were found longitudinally. Similarly, three symptomatological dimensions (negative, disorganized, paranoid) could be extracted by factor analysis in a group of 131 chronic schizophrenic patients (mean duration of illness: $40 \pm 9$ years). These dimensions correspond to those found in younger chronic patients and were independent of the severity of cognitive deficits [52]. Consistent with our results, a recent meta-analysis and review of Heilbronner and colleagues [53] described a rather stable psychopathological profile 
with worsening of cognition in later life associated with neurodegeneration.

In general, NSS in younger patient samples are structurally associated with morphological alterations of pre- and post-central gyri, premotor area, cerebellum, middle and inferior frontal gyri, thalamus and basal ganglia, temporal and lingual gyri, inferior parietal lobule, insula, precuneus and occipital gyrus [for review see: 54, 55].

In addition, Kong et al. [7] found the dichotomisation into patients with decreasing and patients with persistent NSS levels supported by different underlying cerebral changes over time, which were more pronounced in those prone to a rather unfavorable course. These results were extended by findings of a more recent publication about the associations of GM with NSS scores in 49 patients with chronic schizophrenia (mean duration of illness of $20.3 \pm 14.0$ years). We have identified the lingual, parahippocampal, superior temporal, inferior and middle frontal gyri, thalamus and cerebellum as important sites of NSS in chronic schizophrenia [56]. Thus, corresponding to our own longitudinal results [7] we confirmed in our recent study significant negative correlations between GM in frontal and cerebellar regions and NSS scores [56]. These findings support our hypothesis of associations between increasing NSS in patients with chronic schizophrenia, as shown in the present study, and progressive cerebral changes. Taken together these results also correspond with the assumption of a disrupted cortico-cerebellar-thalamic-cortical circuit in schizophrenia, conceptualized as model of "cognitive dysmetria" [57].

Sample size and concomitant diseases have to be considered as potential confounders. However, the follow-up assessment of older patients with a chronic course of the disease was difficult due to the institutionalization of one third of the patients in nursing homes at the second evaluation [see also: 58]. Given the severity of the disease not all patients were able to complete the entire examination. However, a physically healthy sample of middle-aged patients with chronic schizophrenia would be far away from being representative. Indeed, it has been shown-as in our sample-that individuals with schizophrenia have high levels of medical comorbidity and cardiovascular risk factors with high rates of metabolic syndrome of $32.3 \%$ in medicated patients, while the strongest influence on the rate of metabolic syndrome is illness duration [59-61]. In older patients with a mean age of 50 years or higher metabolic syndrome was present in $39.2 \%$, in contrast to approximately $10 \%$ when only first-episode patients were considered [59, 62]. Thus, a poor physical health status may contribute to both, increasing NSS scores and cognitive deficits [22], together with the corresponding cerebral changes, as these parameters seem to worsen over time despite a rather stable psychopathology.
These results underline the need for specific interventions to decrease the respective risk factors, which has been shown to be effective [63]. Also consequent monitoring and treatment of cardiac and metabolic problems [64-67] are necessary, given the high percentage of somatic comorbidities especially in older patients with schizophrenia [68].

Acknowledgements Open Access funding provided by Projekt DEAL. The study was supported by the Dietmar Hopp Foundation and St. Thomas e.V., Germany. Both had no further role in the study design; in the collection, analysis, and interpretation of data; in the writing of the report; or in the decision to submit the paper for publication.

Author contributions $\mathrm{CJH}$ performed data collection, statistical analyses, interpretation of data and wrote the manuscript. CZD supported data collection and statistical analyses. JS designed the study, supervised clinical assessments, contributed to the interpretation of the results and supported critical revision of the manuscript. All authors read and approved the final manuscript.

\section{Compliance with ethical standards}

Conflict of interest The authors declare that they have no conflict of interest.

Ethics approval The investigations were approved by the ethics committee of the Medical Faculty, Heidelberg University (Nr. S-366/2015). Written informed consent was obtained from all participants in accordance with the 1964 Declaration of Helsinki and its later amendments after the procedures of the study had been fully explained.

Open Access This article is licensed under a Creative Commons Attribution 4.0 International License, which permits use, sharing, adaptation, distribution and reproduction in any medium or format, as long as you give appropriate credit to the original author(s) and the source, provide a link to the Creative Commons licence, and indicate if changes were made. The images or other third party material in this article are included in the article's Creative Commons licence, unless indicated otherwise in a credit line to the material. If material is not included in the article's Creative Commons licence and your intended use is not permitted by statutory regulation or exceeds the permitted use, you will need to obtain permission directly from the copyright holder. To view a copy of this licence, visit http://creativecommons.org/licenses/by/4.0/.

\section{References}

1. Heinrichs DW, Buchanan RW (1988) Significance and meaning of neurological signs in schizophrenia. Am J Psychiatry 145(1):11-18

2. Schröder J, Niethammer R, Geider FJ, Reitz C, Binkert M, Jauss M, Sauer H (1992) Neurological soft signs in schizophrenia. Schizophr Res 6(1):25-30. https://doi.org/10.1016/09209964(91)90017-L

3. Schröder J, Heuser M (2008) Neurological soft signs in firstepisode schizophrenia. Dir Psychiatr 28(4):243-258

4. Bombin I, Arango C, Buchanan RW (2005) Significance and meaning of neurological signs in schizophrenia: two decades later. Schizophr Bull 31(4):962-977. https://doi.org/10.1093/schbul/ sbi028 
5. Bachmann S, Degen C, Geider FJ, Schröder J (2014) Neurological soft signs in the clinical course of schizophrenia: results of a meta-analysis. Front Psychiatry 5:185. https://doi.org/10.3389/ fpsyt.2014.00185

6. Bachmann S, Schröder J (2018) Neurological soft signs in schizophrenia: an update on the state- versus trait-perspective. Front Psychiatry. https://doi.org/10.3389/fpsyt.2017.00272

7. Kong L, Bachmann S, Thomann PA, Essig M, Schröder J (2012) Neurological soft signs and gray matter changes: a longitudinal analysis in first-episode schizophrenia. Schizophr Res 134(1):2732. https://doi.org/10.1016/j.schres.2011.09.015

8. Olabi B, Ellison-Wright I, McIntosh AM, Wood SJ, Bullmore E, Lawrie SM (2011) Are there progressive brain changes in schizophrenia? A meta-analysis of structural magnetic resonance imaging studies. Biol Psychiatry 70(1):88-96. https:// doi.org/10.1016/j.biopsych.2011.01.032

9. Kempton MJ, Stahl D, Williams SCR, DeLisi LE (2010) Progressive lateral ventricular enlargement in schizophrenia: a meta-analysis of longitudinal MRI studies. Schizophr Res 120(1-3):54-62. https://doi.org/10.1016/j.schres.2010.03.036

10. Ellison-Wright I, Glahn DC, Laird AR, Thelen SM, Bullmore E (2008) The anatomy of first-episode and chronic schizophrenia: an anatomical likelihood estimation meta-analysis. Am J Psychiatry 165(8):1015-1023

11. Chan RC, Di X, McAlonan GM, Gong QY (2011) Brain anatomical abnormalities in high-risk individuals, first-episode, and chronic schizophrenia: an activation likelihood estimation metaanalysis of illness progression. Schizophr Bull 37(1):177-188. https://doi.org/10.1093/schbul/sbp073

12. Herold CJ, Schmid LA, Lässer MM, Seidl U, Schröder J (2017) Cognitive performance in patients with chronic schizophrenia across the lifespan. GeroPsych 30(1):35-44. https://doi. org/10.1024/1662-9647/a000164

13. Herold CJ, Duval CZ, Lässer MM, Schröder J (2019) Neurological soft signs (NSS) and cognitive impairment in chronic schizophrenia. Schizophr Res Cogn 16:17-24. https://doi. org/10.1016/j.scog.2018.12.002

14. Fioravanti M, Bianchi V, Cinti ME (2012) Cognitive deficits in schizophrenia: an updated metanalysis of the scientific evidence. BMC Psychiatry 12:64

15. Herold CJ, Lässer MM, Schmid LA, Seidl U, Kong L, Fellhauer I, Thomann PA, Essig M, Schröder J (2015) Neuropsychology, autobiographical memory, and hippocampal volume in "younger" and "older" patients with chronic schizophrenia. Front Psychiatry. https://doi.org/10.3389/fpsyt.2015.00053

16. Schmid LA, Lässer MM, Schröder J (2011) Symptomatik und Kognition bei Schizophrenie im Alter. Fortschr Neurol Psychiat 79(5):267-276

17. Harvey PD, Reichenberg A, Bowie CR (2006) Cognition and aging in psychopathology: focus on schizophrenia and depression. Ann Rev Clin Psych 2:389-409. https://doi.org/10.1146/ annurev.clinpsy.2.022305.095206

18. Shah JN, Qureshi SU, Jawaid A, Schulz PE (2012) Is there evidence for late cognitive decline in chronic schizophrenia? Psychiatr Q 83(2):127-144. https://doi.org/10.1007/s1112 6-011-9189-8

19. Herold CJ, Lässer MM, Seidl UW, Hirjak D, Thomann PA, Schröder J (2018) Neurological soft signs and psychopathology in chronic schizophrenia: a cross-sectional study in three age groups. Front Psychiatry 9:98. https://doi.org/10.3389/fpsyt.2018.00098

20. Harvey PD (2001) Cognitive and functional impairments in elderly patients with schizophrenia: a review of the recent literature. Harv Rev Psychiatry 9(2):59-68

21. Cai L, Huang J (2018) Schizophrenia and risk of dementia: a meta-analysis study. Neuropsychiatr Dis Treat 14:2047-2055. https://doi.org/10.2147/NDT.S172933
22. Bora E, Akdede BB, Alptekin K (2017) The relationship between cognitive impairment in schizophrenia and metabolic syndrome: a systematic review and meta-analysis. Psychol Med 47(6):1030 1040. https://doi.org/10.1017/S0033291716003366

23. Cohen CI, Vahia I, Reyes P, Diwan S, Bankole AO, Palekar N, Kehn M, Ramirez P (2008) Schizophrenia in later life: clinical symptoms and social well-being. Psychiatr Serv 59(3):232-234. https://doi.org/10.1176/appi.ps.59.3.232

24. American Psychiatric Association (2000) Diagnostic and statistical manual of mental disorders-DSM-IV-TR (4th edition, Text Revision). APA, Washington

25. Overall JE, Gorham DR (1962) The brief psychiatric rating scale. Psychol Rep 10:799-812

26. Andreasen NC (1984) Scale for the assessment of positive symptoms (SAPS). Department of Psychiatry, College of Medicine, University of Iowa Iowa City, Iowa

27. Andreasen NC (1984) Scale for the assessment of negative symptoms (SANS). Department of Psychiatry, College of Medicine, University of Iowa Iowa City, Iowa

28. Marin RS, Biedrzycki RC, Firinciogullari S (1991) Reliability and validity of the apathy evaluation scale. Psychiatry Res 38:143-162

29. Lueken U, Seidl U, Schwarz M, Völker L, Naumann D, Mattes K, Schröder J, Schweiger E (2006) Psychometric properties of a German version of the apathy evaluation scale. Fortschr Neurol Psychiatr 74(12):714-722. https://doi.org/10.1055/s-2006-93216 4

30. Schröder J, Richter P, Geider FJ, Niethammer R, Binkert M, Reitz C, Sauer H (1993) Discrete motor and sensory disorders (neurologic soft signs) in the acute course of endogenous psychoses. Z Klin Psychol Psychopathol Psychother 41(2):190-206

31. Bachmann S, Bottmer C, Schröder J (2005) Neurological soft signs in first-episode schizophrenia: a follow-up study. Am J Psychiatry 162(12):2337-2343. https://doi.org/10.1176/appi. ajp.162.12.2337

32. Folstein MF, Folstein SE, McHugh PR (1975) "Mini-mental state". A practical method for grading the cognitive state of patients for the clinician. J Psychiatr Res 12(3):189-198

33. Härting C, Markowitsch HJ, Neufeld H, Calabrese PKD, Kessler J (eds) (2000) Deutsche adaptation der revidierten fassung der wechsler memory scale (WMS-R). Verlag Hans Huber, Bern

34. Reitan C (1992) The Trail Making Test: Manual For Administration And Scoring. The Reitan Neuropsychological Laboratory, Tucson

35. Morris JC, Heyman A, Mohs RC, Hughes JP, van Belle G, Fillenbaum G, Mellits ED, Clark C (1989) The consortium to establish a registry for Alzheimer's disease (CERAD). Part I. Clinical and neuropsychological assessment of Alzheimer's disease. Neurology 39(9):1159-1165

36. Smith RC, Hussain MI, Chowdhury SA, Stearns A (1999) Stability of neurological soft signs in chronically hospitalized schizophrenic patients. J Neuropsychiatry Clin Neurosci 11(1):91-96

37. Chen EYH, Kwok CL, Au JWY, Lau BST, Chen RYL (2000) Progressive deterioration of soft neurological signs in chronic schizophrenic patients. Acta Psychiatr Scand 102(5):342-349

38. Chan RCK, Cui HR, Chu MY, Zhang TH, Wang Y, Wang Y, Li Z, Lui SSY, Wang JJ, Cheung EFC (2018) Neurological soft signs precede the onset of schizophrenia: a study of individuals with schizotypy, ultra-high-risk individuals, and first-onset schizophrenia. Eur Arch Psychiatry Clin Neurosci 268(1):49-56. https://doi. org/10.1007/s00406-017-0828-4

39. Feng Y, Wang Z, Lin G, Qian H, Gao Z, Wang X, Li M, Hu X, Li $Y$ (2020) Neurological soft signs and neurocognitive deficits in remitted patients with schizophrenia, their first-degree unaffected relatives, and healthy controls. Eur Arch Psychiatry Clin Neurosci 270(3):383-391. https://doi.org/10.1007/s00406-019-01024-x 
40. Fucetola R, Seidman LJ, Kremen WS, Faraone SV, Goldstein JM, Tsuang MT (2000) Age and neuropsychologic function in schizophrenia: a decline in executive abilities beyond that observed in healthy volunteers. Biol Psychiatry 48(2):137-146

41. Loewenstein DA, Czaja SJ, Bowie CR, Harvey PD (2012) Ageassociated differences in cognitive performance in older patients with schizophrenia: a comparison with healthy older adults. Am J Geriatr Psychiatry 20(1):29-40. https://doi.org/10.1097/ JGP.0b013e31823bc08c

42. Bowie CR, Reichenberg A, McClure MM, Leung WL, Harvey PD (2008) Age-associated differences in cognitive performance in older community dwelling schizophrenia patients: differential sensitivity of clinical neuropsychological and experimental information processing tests. Schizophr Res 106(1):50-58. https://doi. org/10.1016/j.schres.2007.10.026

43. Heaton RK, Gladsjo JA, Palmer BW, Kuck J, Marcotte TD, Jeste DV (2001) Stability and course of neuropsychological deficits in schizophrenia. Arch Gen Psychiatry 58(1):24-32

44. Savla GN, Moore DJ, Roesch SC, Heaton RK, Jeste DV, Palmer BW (2006) An evaluation of longitudinal neurocognitive performance among middle-aged and older schizophrenia patients: use of mixed model analyses. Schizophr Res 83:215-223

45. Kirkpatrick B, Messias E, Harvey PD, Fernandez-Egea E, Bowie CR (2008) Is schizophrenia a syndrome of accelerated aging? Schizophr Bull 34(6):1024-1032. https://doi.org/10.1093/schbu $1 / \mathrm{sbm} 140$

46. Kraepelin E (1913) Psychiatrie. Ein Lehrbuch für Studierende und Ärzte., vol Band III, Teil 2, 8. Aufl. Johann Ambrosius Barth, Leipzig

47. Degen C, Toro P, Schönknecht P, Sattler C, Schröder J (2016) Diabetes mellitus Type II and cognitive capacity in healthy aging, mild cognitive impairment and Alzheimer's disease. Psychiatry Res 240:42-46. https://doi.org/10.1016/j.psychres.2016.04.009

48. Toro P, Schönknecht P, Schröder J (2009) Type II diabetes in mild cognitive impairment and Alzheimer's disease: results from a prospective population-based study in Germany. J Alzheimer's Dis 16(4):687-691

49. Gross G, Huber G, Schüttler R, Hasse-Sander I (1971) Uncharakteristische Remissionstypen im Verlauf schizophrener Erkrankungen. In: Huber G (ed) Ätiologie der Schizophrenien: Bestandsaufnahme und Zukunftsperspektiven. Schattauer, Stuttgart, pp 201-214

50. Huber G, Gross G, Schüttler R (1979) Schizophrenie. Eine Verlaufs- und sozialpsychiatrische Langzeitstudie. Monographien aus dem Gesamtgebiete der Psychiatrie, Springer, Berlin

51. Janzarik W (1968) Schizophrene Verläufe. Eine strukturdynamische Interpretation. Monographien aus dem Gesamtgebiete der Neurologie und Psychiatrie, Springer, Berlin

52. Sauer H, Hornstein C, Richter P, Mortimer A, Hirsch SR (1999) Symptom dimensions in old-age schizophrenics. Relationship to neuropsychological and motor abnormalities. Schizophr Res 39(1):31-38. https://doi.org/10.1016/s0920-9964(99)00017-1

53. Heilbronner U, Samara M, Leucht S, Falkai P, Schulze TG (2016) The longitudinal course of schizophrenia across the lifespan: clinical, cognitive, and neurobiological aspects. Harv Rev Psychiatry 24(2):118-128. https://doi.org/10.1097/HRP.0000000000000092

54. Zhao Q, Li Z, Huang J, Yan C, Dazzan P, Pantelis C, Cheung EF, Lui SS, Chan RC (2014) Neurological soft signs are not "soft" in brain structure and functional networks: evidence from ALE metaanalysis. Schizophr Bull 40(3):626-641. https://doi.org/10.1093/ schbul/sbt063
55. Hirjak D, Thomann PA, Kubera KM, Wolf ND, Sambataro F, Wolf RC (2015) Motor dysfunction within the schizophrenia-spectrum: a dimensional step towards an underappreciated domain. Schizophr Res 169(1-3):217-233. https://doi.org/10.1016/j.schre s.2015.10.022

56. Herold CJ, Essig M, Schröder J (2020) Neurological soft signs (NSS) and brain morphology in patients with chronic schizophrenia and healthy controls. PLoS ONE 15:0231669

57. Andreasen NC, Paradiso S, O'Leary DS (1998) 'Cognitive dysmetria' as an integrative theory of schizophrenia: a dysfunction in cortical-subcortical-cerebellar circuitry? Schizophr Bull 24(2):203-218

58. Andrews AO, Bartels SJ, Xie H, Peacock WJ (2009) Increased risk of nursing home admission among middle aged and older adults with schizophrenia. Am J Geriatr Psychiatry 17(8):697705. https://doi.org/10.1097/JGP.0b013e3181aad59d

59. Mitchell AJ, Vancampfort D, Sweers K, van Winkel R, Yu W, De Hert M (2013) Prevalence of metabolic syndrome and metabolic abnormalities in schizophrenia and related disorders-a systematic review and meta-analysis. Schizophr Bull 39(2):306-318. https://doi.org/10.1093/schbul/sbr148

60. Ringen PA, Engh JA, Birkenaes AB, Dieset I, Andreassen OA (2014) Increased mortality in schizophrenia due to cardiovascular disease-A non-systematic review of epidemiology, possible causes, and interventions. Front Psychiatry 5:137

61. de Hert M, Schreurs V, Vancampfort D, van Winkel R (2009) Metabolic syndrome in people with schizophrenia: a review. World Psychiatry 8(1):15-22

62. Mitchell AJ, Vancampfort D, De Herdt A, Yu W, De Hert M (2013) Is the prevalence of metabolic syndrome and metabolic abnormalities increased in early schizophrenia? A comparative meta-analysis of first episode, untreated and treated patients. Schizophr Bull 39(2):295-305. https://doi.org/10.1093/schbul/ sbs082

63. Gurusamy J, Gandhi S, Damodharan D, Ganesan V, Palaniappan M (2018) Exercise, diet and educational interventions for metabolic syndrome in persons with schizophrenia: a systematic review. Asian J Psychiatr 36:73-85. https://doi.org/10.1016/j. ajp.2018.06.018

64. Heald A (2010) Physical health in schizophrenia: a challenge for antipsychotic therapy. Eur Psychiatr 25(Suppl 2):S6-S11. https:// doi.org/10.1016/S0924-9338(10)71700-4

65. Montejo AL (2010) The need for routine physical health care in schizophrenia. Eur Psychiatr 25(Suppl 2):S3-S5. https://doi. org/10.1016/S0924-9338(10)71699-0

66. Chaudhry IB, Jordan J, Cousin FR, Cavallaro R, Mostaza JM (2010) Management of physical health in patients with schizophrenia: international insights. Eur Psychiatr 25(Suppl 2):S37S40. https://doi.org/10.1016/S0924-9338(10)71705-3

67. McDaid TM, Smyth S (2015) Metabolic abnormalities among people diagnosed with schizophrenia: a literature review and implications for mental health nurses. J Psychiatr Ment Health Nurs 22(3):157-170. https://doi.org/10.1111/jpm.12185

68. Arbus C, Clement J-P, Bougerol T, Fremont S, Lancrenon S, Camus V (2012) Health management of older persons with chronically medicated psychotic disorders: the results of a survey in France. Int Psychogeriatr 24(3):496-502. https://doi.org/10.1017/ S1041610211001487 